\title{
Erratum to: Sustainable Management of Fisheries and Aquaculture for Food Security and Nutrition: Policies Requirements and Actions
}

\author{
Martin S. Kumar
}

Published online: 6 August 2014

(C) NAAS (National Academy of Agricultural Sciences) 2014

Erratum to: Agric Res (June 2014) 3(2):97-103

DOI 10.1007/s40003-014-0111-0

The affiliation of the author was incorrectly published in the original article. The author's correct affiliation appears in this erratum.

The online version of the original article can be found under doi:10.1007/s40003-014-0111-0.

M. S. Kumar $(\bowtie)$

School of Biological Sciences, Flinders University, Adelaide, SA, Australia

e-mail: martin.kumar@senet.com.au 